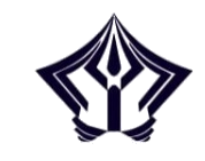

ANFUSINA: JOURNAL OF PSYCHOLOGY

http://ejournal.radenintan.ac.id/index.php/anfusina

DOI: //dx.doi.org/10.24042/ajp.v2i2.5688

Volume 2, Nomor 2, Oktober Tahun 2019

\title{
Pengaruh Cognitive Behavior Therapy Dalam Menurunkan Anxiety Sebagai Upaya Optimalisasi Fungsi Mental Pasien Kanker Serviks
}

\begin{tabular}{c}
\hline Junaidi \\
Universitas Malahayati Lampung \\
junaidi@ gmail.com \\
\hline
\end{tabular}

\begin{abstract}
Until now, cervical cancer is still a cause of female mortality which is quite high, estimated at 4,900 people per year. When doctors diagnose a person suffering from a dangerous (chronic) disease such as cancer, there are three forms of emotional responses that may generally appear, namely rejection, anxiety and depression. Anxiety that often occurs in cervical cancer patients is a negative emotion that causes individuals to feel afraid, worried and concerned about something, the source is realistic or not, and ultimately motivates the individual to take concrete action in response to the existing anxiety.

This study was conducted to examine the effect of CBT therapy in reducing anxiety levels of cervical cancer patients, using quantitative and qualitative research methods. The combination of quantitative and qualitative methods will help researchers to better understand the phenomenon being studied. The quantitative method in this study uses descriptive analysis.

Based on the results obtained from this study, it was seen that there was a decrease in the degree of anxiety in cervical cancer patients who were the subject of this study after being intervened by using cognitive behavior therapy (CBT).

An effective change occurs in cervical cancer sufferers after being given CBT therapy where positive effects are felt such as feeling calmer, more energetic and optimistic to recover in the face of the disease. Giving CBT therapy makes the process of cognitive assessment of patients to change. Social support that comes from families such as husband and children and the surrounding environment can provide strength and motivation to recover for patients with cervical cancer
\end{abstract}




\begin{abstract}
Abstrak
Sampai saat ini kanker serviks masih menjadi penyebab dari kematian wanita yang cukup tinggi, diperkirakan sebesar 4.900 orang per tahun. Ketika dokter mendiagnosa bahwa seseorang menderita penyakit berbahaya (kronis) seperti kanker, ada tiga bentuk respons emosional yang secara umum mungkin muncul, yaitu penolakan, kecemasan dan depresi. Kecemasan yang sering terjadi pada pasien kanker serviks merupakan suatu emosi negatif yang menyebabkan individu merasa takut, khawatir dan prihatin tentang sesuatu, yang sumbernya realistis maupun tidak, dan pada akhirnya memotivasi individu untuk melakukan tindakan nyata sebagai respon terhadap kecemasan yang ada.

Penelitian ini dilakukan untuk menguji pengaruh dari terapi CBT dalam menurunkan tingkat kecemasan pasien kanker serviks, dengan menggunakan metode penelitian kuantitatif dan kualitatif. Gabungan dari metoda kuantitatif dan kualitatif akan membantu peneliti untuk lebih mengerti fenomena yang sedang diteliti. Metoda kuantitatif pada penelitian ini menggunakan analisis deskriptif.

Berdasarkan hasil yang diperoleh dari penelitian ini, terlihat bahwa terjadi penurunan derajat anxiety pada pasien kanker seviks yang menjadi subjek penelitian ini setelah di intervensi dengan menggunakan cognitive behavior therapy (CBT).

Terjadi perubahan yang efektif pada penderita kanker serviks setelah diberikan terapi CBT dimana muncul dampak positif yang dirasakan seperti perasaan lebih tenang, lebih semangat dan optimis untuk sembuh dalam menghadapi penyakitnya. Pemberian terapi CBT ini membuat proses penilaian kognitif pasien menjadi berubah. Social support yang datang dari keluarga seperti suami dan anak serta lingkungan sekitar dapat memberikan kekuatan dan motivasi untuk sembuh bagi pasien kanker seviks.
\end{abstract}

Keywords: cognitive behavior therapy, servical cancer

\title{
Pendahuluan
}

Kanker adalah suatu kata yang sangat menakutkan bagi setiap orang. Bila seseorang diketahui menderita kanker, berarti orang tersebut menderita suatu penyakit yang sangat parah atau akan menemui kematian. Demikian pula halnya ketika terkait dengan kanker serviks atau yang lebih dikenal dengan kanker leher rahim. Sebagai kasus yang terbanyak ditemukan pada perempuan selain kanker payudara, kanker serviks di Indonesia belum tertata laksana dengan baik. Dibutuhkan perhatian intensif untuk dapat mengurangi faktor resiko yang lebih besar lagi. Penyakit kanker serviks ini berdampak pada penurunan kualitas sumber daya manusia, karena 
komplikasi menahun serta mahalnya biaya penanganan komplikasi. Namun, menurut para ahli kanker, kanker serviks adalah salah satu jenis kanker yang paling dapat dicegah dan paling dapat disembuhkan dari semua jenis kanker. Sampai saat ini kanker serviks masih menjadi penyebab dari kematian wanita yang cukup tinggi, diperkirakan sebesar 4.900 orang per tahun (Berek, 1996). Dengan peningkatan kasus kanker yang begitu memprihatinkan, diperkirakan 20 persen pertahun diseluruh dunia, penanganan kanker di Indonesia perlu diperbaiki. Selain program-programnya harus lebih strategis dan komprehensif, tantangan utamanya adalah bagaimana memeratakan pengetahuan dan pelayanan kesehatan hingga keseluruh tanah air dan akhirnya banyak pasien kanker bisa terselamatkan.

Suriyaman (2002) menemukan angka kejadian kanker serviks di Indonesia mencapai $\pm 150-180$ per 100.000 penduduk dan prevalensi kanker serviks sekitar $11 \%$ dari semua kasus kanker pada wanita dan $66 \%$ dari kanker genitalia pada wanita.

Ketika dokter mendiagnosa bahwa seseorang menderita penyakit berbahaya (kronis) seperti kanker, ada tiga bentuk respons emosional yang secara umum mungkin muncul, yaitu penolakan, kecemasan dan depresi (Taylor, 1988). Bagi seorang wanita, rahim mempunyai arti biologis dan psikologis. Hal ini menimbulkan respon psikologis berupa kecemasan pada wanita yang terdiagnosis kanker serviks. Dalam keadaan tersebut sangat sulit bagi pasien kanker untuk dapat menerima dirinya karena keadaan dan penanganan penyakit kanker ini dapat menimbulkan stres yang terus menerus, sehingga tidak hanya mempengaruhi penyesuaian fisik tetapi juga penyesuaian psikologis individu (Lehman dkk, 1978).

Kecemasan juga akan meningkat ketika individu membayangkan terjadinya perubahan dalam hidupnya dimasa depan akibat dari penyakit yang diderita ataupun akibat dari proses penanganan suatu penyakit, serta mengalami kekurangan informasi mengenai sifat suatu penyakit dan penanganannya.

Timbulnya kecemasan ini menimbulkan berbagai perubahan sistem fisiologis tubuh untuk beradaptasi dan mempertahankan kondisi normal. Akibat yang buruk dapat terjadi apabila kecemasan berkepanjangan. Hal ini dapat merusak fungsi otak dan menurunkan sistem kekebalan tubuh (Corwin, 1996; Carol, 1998; Notosoedirdjo, 2004). Kondisi ini menyebabkan kerusakan jaringan oleh sel kanker bertambah luas dan cepat menyebar ke jaringan lain. Akibatnya umur harapan hidup pasien semakin pendek (Mamik dan Setiawan, 2003). 
Kecemasan yang sering terjadi pada pasien kanker serviks merupakan suatu emosi negatif yang menyebabkan individu merasa takut, khawatir dan prihatin tentang sesuatu, yang sumbernya realistis maupun tidak, dan pada akhirnya memotivasi individu untuk melakukan tindakan nyata sebagai respon terhadap kecemasan yang ada. Kecemasan merupakan salah satu bentuk reaksi terhadap adanya stress maupun frustasi. Spielberger (1966) menerangkan terdapat 2 (dua) macam kecemasan yaitu kecemasan sebagai suatu keadaan (state anxiety) dan kecemasan sebagai suatu trait (trait anxiety).

Pemeriksaan secara rutin terkadang menimbulkan stress tersendiri dalam diri individu karena mengingatkan bahwa mereka menderita kanker. Kenyataan yang diungkapkan oleh lingkungan yang tiba-tiba berubah memperhatikan, memperlakukan secara berlebihan, mengutamakan segala yang ada pada diri seseorang ataupun kenyataan yang diungkapkan langsung oleh dokter kepada penderita bahwa dia menderita kanker, segera menyadarkan diri individu akan saat kematiannya karena kanker serviks menyebabkan risiko kematian bagi penderita relatif sangat tinggi.

Dengan demikian diperlukan strategi yang efektif untuk menurunkan kecemasan pasien kanker serviks atau leher rahim antara lain melalui teknik Cognitive Behavior Therapy. Terapi ini menekankan pentingnya perubahan kognitif dan prilaku untuk mengurangi simptom dan meningkatkan fungsi afek seseorang.

\section{Metode Penelitian}

Penelitian ini dilakukan untuk menguji pengaruh dari terapi CBT dalam menurunkan tingkat kecemasan pasien kanker serviks, dengan menggunakan metode penelitian kuantitatif dan kualitatif. Gabungan dari metoda kuantitatif dan kualitatif akan membantu peneliti untuk lebih mengerti fenomena yang sedang diteliti. Metoda kuantitatif pada penelitian ini menggunakan analisis deskriptif. Alat ukur yang digunakan didalam analisa kuantitatif ini adalah STAI Z-1 dan Z-2 diciptakan oleh Charles D. Spielberger bersama Richard L. Gorsuch dan Robert E. Lushene yang dikonstruksi mulai tahun 1964. Alat ukur ini merupakan Self Report yang bertujuan untuk mengukur 2 (dua) konsep kecemasan yang berbeda, yaitu: State Anxiety atau disingkat A-State dan Trait Anxiety atau disingkat A-Trait. Analisa kualitatif dilakukan dengan mendeskripsikan secara objektif dan 
sistematis hasil data yang diperoleh melalui observasi dan wawancara.

\section{Hasil dan Pembahasan}

Subjek yang digunakan didalam penelitian ini sebanyak 4 (empat) orang. Berikut ini akan ditampilkan skor total dari keseluruhan subyek baik pada pre dan post treatment dengan menggunakan STAI :

\section{Tabel 1.}

skor subjek pre post treatment (state dan trait anxiety)

$\begin{array}{ccccc} & \text { Treatment State } & \text { Treatment State } & \text { Treatment Trait } & \text { Treatment Trait } \\ \text { Noma } & \text { anxiety } & \text { anxiety } & \text { anxiety } & \text { anxiety } \\ \text { NO Subjek } & \text { Pre } & \text { Post } & \text { Pre } & \text { Post }\end{array}$

$\begin{array}{ccccccccc}\text { Pre } & \text { Pre } & \text { Kategori } & \text { Post } & \text { Post } & \text { Kategori Nilai } & \text { Kategori Nilai } & \text { Kategori } \\ 1 & 2 & & 1 & 2 & & & & \end{array}$

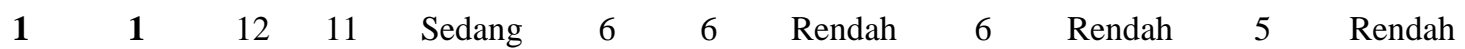

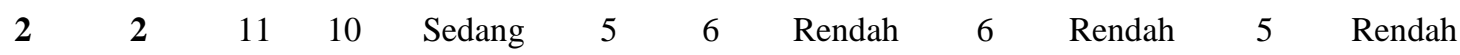

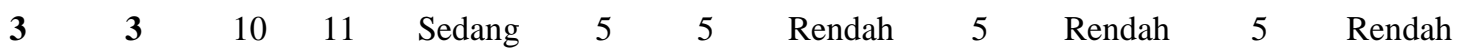

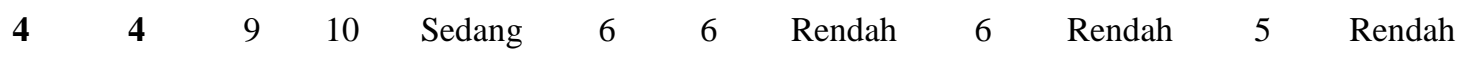




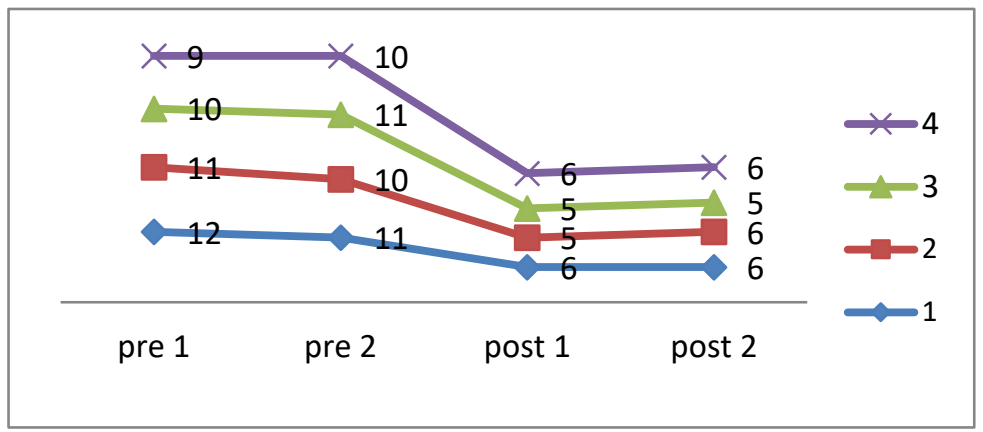

\section{Gambar 1. \\ Grafik penurunan state anxiety setelah pemberian treatment}

Bila kita lihat secara keseluruhan bahwa semua subyek seperti subjek 1, 2, 3 dan 4 setelah diberikan treatment akan mengalami penurunan pada skor yang diperoleh. Hal ini menunjukkan bahwa terapi CBT memiliki pengaruh yang signifikan untuk menurunkan kecemasan pasien kanker serviks.

Berdasarkan hasil yang diperoleh dari penelitian ini, terlihat bahwa terjadi penurunan derajat anxiety pada pasien kanker seviks yang menjadi subjek penelitian ini setelah di intervensi dengan menggunakan cognitive behavior therapy (CBT). Hasil ini terlihat dengan terjadinya penurunan dan perubahan kategori anxiety pada keempat pasien yaitu pada pengukuran Y1 dan pengukuran Y3, dimana pengukuran Y1 dilakukan sebelum intervensi diberikan dan pengukuran Y3 yang diberikan 2 (dua) bulan setelah pengukuran Y3 atau setelah sesi kedelapan dari intervensi dilakukan. Pada subjek 1 terjadi penurunan kategori dari kategori sedang kekategori rendah, subjek 2 terjadi penurunan kategori dari kategori sedang kekategori rendah, subjek 3 terjadi penurunan kategori dari kategori sedang kekategori rendah dan begitu juga subjek 4 terjadi penurunan kategori dari kategori sedang kekategori rendah. Keadaan mengenai keefektifan dari intervensi ini diperkuat pula dengan tidak terjadinya perubahan kategori antara Y2 dan Y4 yang memiliki jarak 2 (dua) bulan lamanya, dimana antara pengukuran Y2 dan Y4 tidak dilakukan intervensi apapun.

Hasil penelitian ini juga menemukan bahwa faktor nervounness keempat pasien seperti ketegangan, kekhawatiran, ketakutan, gugup, gelisah, kebingungan dan penolakan lebih berperan dibandingkan faktor well-being seperti keamanan, ketentraman, kepuasan, kenyamanan, kemakmuran dan kebahagian, baik pada saat sebelum 
pengukuran maupun setelah pengukuran dilakukan, hal tersebut ditandai dari nilai faktor nervousnness yang lebih besar dibandingkan dengan nilai faktor well-being, namun juga pada setiap pasien terjadi penurunan yang cukup signifikan setelah dilakukan treatment hal ini berarti pengaruh terapi memiliki peran terhadap penurunan faktor nervousnness dan faktor well-being.

Keempat pasien kanker serviks tersebut merasa selalu dibayangi oleh ketakutan terhadap adanya perubahan dalam hidupnya bahkan kematian. Subjek pertama merasakan ketegangan, shock dan tidak percaya atas diagnosa dokter, merasa stres berat, takut, cemas, panik dan bingung sehingga hanya bisa menangis. Subjek ke- 2 merasa kaget dan takut setelah didiagnosa dokter, merasa cemas, panik dan bingung. Subjek ke-3 ketika didiagnosa dokter merasa bingung, cemas, takut dan juga hanya bisa bersedih. Begitu pula dengan yang dirasakan subjek ke-4, dia merasa kaget, takut, dan sedih ketika dokter pertama kali mendiagnosa penyakitnya.

Kekhawatiran yang berlebihan terhadap penyakit kanker dapat menimbulkan berbagai reaksi kognitif, psikologis dan fisiologis penderita kanker serviks. Reaksi kognitif yang dialami subjek 1, 2, 3, dan 4 misalnya takut, khawatir, membesar-besarkan ancaman dan memandang diri tidak berdaya. Reaksi fisiologis yang timbul misalnya sulit bernafas, dada sesak, berat badan menurun, tekanan darah meningkat, cepat lelah, ketegangan otot ditangan dan kaki serta sakit kepala dimana kepala terasa berat karena ketegangan yang dialami sedangkan reaksi-reaksi psikologis yang mereka alami dapat muncul berupa cemas, takut, kaget, tegang, bingung sedih, merasa bersalah, marah, putus asa, menganggap diri buruk dan sensitif sedangkan. Reaksi kognitif, fisiologis dan psikologis ini saling berkaitan satu sama lainnya. Pengukuran kecemasan yang dilakukan sebelum treatment diberikan diperoleh bahwa tingkat kecemasan penderita kanker serviks berada pada kategori sedang untuk state dan kategori rendah untuk trait. Subjek 1 memperoleh nilai state 12, 11 dan trait 6 , subjek 2 nilai state 11, 10 dan trait 6 , subjek 3 nilai state 10, 11 dan trait 5 serta subjek 4 nilai state 9,10 dan trait 6 . Hal ini menandakan bahwa memang karena kondisinya yang mengalami kanker serviks sehingga memunculkan respon kecemasan bukan karena faktor kepribadiannya yang pencemas dalam berbagai situasi.

Pemberian terapi CBT ini membuat proses penilaian kognitif pasien menjadi berubah. Cognitive Behavior Therapy adalah suatu treatmen untuk membantu cara berpikir individu agar menjadi lebih rasional dengan prinsip dan sikap perilaku pada umumnya, agar 
mempunyai kemampuan untuk mengenali dan kemudian mengevaluasi atau mengubah cara berpikir, keyakinan dan perasaannya (mengenai diri sendiri dan lingkungan) yang salah sehingga mereka dapat mengubah perilaku maladaptif menjadi adaptif.

Pada diri subjek 1, 2, 3 dan 4, kecemasan yang dialaminya dipengaruh oleh isi dan proses kognitif yang maladaptif, dimana terus-menerus memikirkan bahwa penyakitnya sangat berbahaya, ancaman akan kematian, merasa tidak berguna serta pemikiranpemikiran negatif lainnya seperti khawatir terhadap suami dan anaknya, pekerjaan yang tidak bisa dilakukannya di rumah/toko/sekolah dan banyaknya pengobatan yang masih harus dijalani. Gangguan kecemasan dalam hal ini dipengaruhi oleh adanya kesadaran pikiran yang terus menggambarkan akan adanya bahaya atau ancaman terhadap semua situasi yang dialami. Kecemasan ini terjadi karena persepsi eksternal dan internal yang terjadi pada individu terhadap suatu ancaman.

Cognitive Behavior Therapy yang digunakan pada penelitian ini disusun dengan mengacu pada beberapa teori dari Kanfer, dkk ((1984); George \& Cristiani (1981); Oemarjadi (2004) yang mempergunakan metode mind over mood, yaitu pasien diajak untuk mengenali, memahami dan akhirnya mengubah perasaan, pikiran dan perilakunya yang negatif. Indikator keberhasilan diketahui dari kemampuan subjek dalam mengerjakan dan melaksanakan tugastugas yang disajikan dalam terapi kognitif prilaku selama pemberian terapi. Semakin menurun distorsi kognitif subjek, maka semakin baik subjek tersebut dalam mengelola kognitifnya sehingga dapat menurunkan tingkat kecemasannya.

Ketika pasien 1, 2, 3 dan 4 telah melakukan terapi ini selama 7 (tujuh) kali pertemuan diharapkan mereka merasakan ada perubahan pada dirinya. Hal yang paling dirasakan oleh mereka adalah pikirannya menjadi lebih tenang karena tidak memikirkan halhal negatif lainnya. Hal ini turut mempengaruhi kelenjar hypothalamus yang berada di otak dalam memberikan penilaian kognitif. Pikiran yang lebih tenang membuat aktivasi kelenjar hypothalamus menjadi tidak berlebihan, sehingga reaksi-reaksi kecemasan yang muncul juga menjadi berkurang. Tubuh mereka juga sudah lebih baik, sakit kepala berangsur-angsur hilang, nafas tidak sesak lagi, tidak merasa cepat lelah dan sudah bisa tidur dengan nyenyak dimalam hari.

\section{Simpulan dan Saran}


Berdasarkan hasil penelitian yang menganalisa data kuantitatif maupun kualitatif, maka dapat ditarik kesimpulan sebagai berikut:

1. Terjadi perubahan yang efektif pada penderita kanker serviks setelah diberikan terapi CBT dimana muncul dampak positif yang dirasakan seperti perasaan lebih tenang, lebih semangat dan optimis untuk sembuh dalam menghadapi penyakitnya. Sebelum melakukan terapi CBT ini, taraf kecemasan subyek berada pada kategori sedang, namun ketika telah melakukan terapi, taraf kecemasan mengalami penurunan yang berada pada kategori rendah. Hasil pengukuran untuk state-anxiety menunjukkan bahwa untuk dimensi faktor nervousness misalnya ketegangan, kekhawatiran, ketakutan, gugup, gelisah, kebingungan dan penolakan sudah tidak dirasakan lagi oleh subjek. Namun, untuk dimensi faktor well-being keamanan, ketentraman, kepuasan, kenyamanan, kemakmuran dan bahagia, masih belum dirasakan karena subjek belum dinyatakan sembuh dari penyakitnya.

2. Pemberian terapi CBT ini membuat proses penilaian kognitif pasien menjadi berubah. Cognitive Behavior Therapy ini merupakan suatu treatmen yang membantu cara berpikir pasien kanker serviks menjadi lebih rasional dengan prinsip dan sikap perilaku pada umumnya, agar mempunyai kemampuan untuk mengenali dan kemudian mengevaluasi atau mengubah cara berpikir, keyakinan dan perasaannya (mengenai diri sendiri dan lingkungan) yang salah sehingga mereka dapat mengubah perilaku maladaptif menjadi adaptif. Serta terjadi perubahan pada proses berpikirnya, dari kognisinya yang negatif menjadi positif, dari pola pemikiran yang sempit menjadi luas, bahwa ada sesuatu yang positif dengan dirinya, lingkungannya dan masa depannya yang dapat dilalui tanpa harus menyalahkan diri, lingkungan dan dunia.

3. Social support yang datang dari keluarga seperti suami dan anak serta lingkungan sekitar dapat memberikan kekuatan dan motivasi untuk sembuh bagi pasien kanker seviks. 
Adapun saran adalah sebagai berikut

1) Pihak rumah sakit perlu memberikan perhatian khusus terhadap kondisi psikologis pasien kanker serviks ketika melakukan pengobatan di rumah sakit. Metode Cognitive Behavior Therapy ini dapat dijadikan metode pendamping bagi metode kedokteran, dengan memberikan fasilitas penunjang sarana dan prasarana psikologi yang layak demi kemajuan pengobatan untuk penderita pasien kanker serviks.

2) Disarankan agar subjek penelitian dapat melakukan terapi ini secara tepat, teratur dan konsisten.

3) Diharapkan subjek dapat menerapkan terapi ini dalam menghadapi situasi-situasi lainnya yang dapat memunculkan kecemasan karena dianggap sebagai situasi yang mengancam.

\section{Referensi}

Berek,J.S.(1996). Novak's Gynecology (12 ${ }^{\text {th }}$ ed.) Balt-more: Williams \& Wilkins

Burish,T.G., Carey, M.P., Krozey, M.G. \& Greco, F.A. (1987) Conditioned Side Effects Induced by Cancer Chemotherapy : Prevention Throug Behavioral Treatment. Journal of Counsulting and Clinical Psychology, 42-48

Burn, D.D.MD. (1988). Terapi Kognitif, Pendekatan Baru Bagi Penanganan Depresi. alih bahasa : DES. Santosa. Penerbit Erlangga

Corwin, Elizabeth J. (1996). Handbook of Pathophysiology. Pendit, Brahm U.(2001) (Alih Bahasa). Jakarta:EGC.

George. R.L \& Cristiani. T.S (1981) Theory, Methods and Processes of Counseling and Psychotherapy New Jersey : Prentice-Hall, Inc

Hudak,C.M., Gallo B.M., and Morton, P. G.(1998). Critical Care Nursing:a Holistic Approach. $\left(7^{\text {th }}\right.$ ed). USA: Lippincott-Raven Publishers. 
Kanfer, F, II \& Goldstein, A.(1984) Helping People Change : A Text book of Methods. New York : Pergamon Press, Inc

Kaplan, R.M., Sallis, J.F., \& Patterson, T.L. (1993) Health and Human Behavior. USA McGraw-Hill Inc

Kay. (2004). Life after Cancer. American Cancer Society. available: http://www.cancer.org/docrot/MBC/content/MBC 4 IX Life after Cancer

Lehman J. F, DeLisa, J.A, Warren, C.G, DeLateur, B.J, Bryant, P.L, \& Nicholson, C.G. (1978). Assesment of Need, Development, and Evaluation of a Model of Care. Arch.Phys. Med. Rehabil, 410-419

Mamik dan Setiawan (2003). Probabilitas Kumulatif Kehidupan Kanker Leher Rahim, Radioterapi RSUD Dr. Soetomo Surabaya. Jurnal Penelitian Politeknik Kesehatan Surabaya. Vol.1, No.1

Mulyadi (1997) Kanker, Karsinogen, Karsinogenesis, dan Antikanker. Yogyakarta. Penerbit : PT. Tiara Wacana

Notosoedirdjo. (2004). Psikobiologi sebagai dasar Psikoneuroimunologi. Surabaya: Gideon Offset Printing

Popkin, M.K. (1988) Prevalence of Major Depression, Simple Phobia and Other Psychiatric Disorders in Patients with Longstanding Type A. Diabetes Melitus. Archieves of General Psychiatry

Prokop, C.K., Bradley L.A., Burish T.G., Anderson, K.O., \& Fox, J.E. (1991) Health Psychology: Clinical Methods \& Research. Newyork : MacMillan Publishing Company.

Prout, II.T \& Brown. D.T (1985) Counseling and Psychotherapy With Children and Adolescents : Theory and Practice for School and Clinical Settings, Brandon, Vermont : Clinical Psychology Publishing Co Inc

Redd,W.H. \& Jacobsen. P.B (1988) Emotions and Cancer : New Perspective on Old Question. Cancer

Suriyaman. (2002). Uji Validitas dan Reliabilitas Instrumen kualitas Hidup dengan Aplikasinya pada Penderita Karsinoma Serviks Stadium Lanjut. Tesis/Karya Ilmiah Program Pendidikan Spesialis I Bidang Studi Obstetri dan Ginekologi Fakultas Kedokteran Tidak Dipublikasikan, Universitas Gadjah Mada, Yogyakarta. 
Junaidi

Spielberger, C. D (1966) Anxiety and Behavior. New York and London: Academic Press

Taylor, S.E \& Dakof. (1988). Social Support and the cancer patient. Newburry park. CA. Sage. The Social Psychology of Healt pp. $95-116$ 